\title{
What observer rats don't learn about foods from demonstrator rats
}

\author{
BENNETT G. GALEF, JR., ELAINE E. WHISKIN, and CHRISTOPHER S. HORN \\ McMaster University, Hamilton, Ontario, Canada
}

\begin{abstract}
Naive "observer" rats that interact with conspecific "demonstrators" fed a distinctive food increase intake of the food their demonstrators have eaten. Here we found that observer rats that had interacted simultaneously with 2 demonstrator rats, 1 fed a distinctively flavored, protein-poor food, the other a distinctively flavored, protein-rich food, did not prefer the former. Similarly, observer rats ate equal amounts of two distinctively flavored foods after interacting simultaneously with 2 demonstrator rats, 1 that had consumed all food available to it, the other fed from a surplus of the second food. Last, observer rats that had interacted with both a "trustworthy" demonstrator (1 an observer had learned ate only nutritious foods) and an "untrustworthy" demonstrator ( 1 an observer had learned ate noxious substances) did not prefer unfamiliar foods eaten by trustworthy demonstrators to those eaten by untrustworthy demonstrators. These findings suggest limits on social information observers use in selecting foods.
\end{abstract}

After interacting briefly with a recently fed rat (a demonstrator), a naive rat (an observer) exhibits substantial enhancement of its relative intake of whatever food its demonstrator has eaten (Galef \& Wigmore, 1983). Analyses of the behavioral processes involved in such social influence on food choice indicate that Norway rats (Rattus norvegicus) do not produce specialized "signals" that provide information about ingested foods. Rather, observers are influenced in their food choices by olfactory cues that are emitted passively by demonstrators as a consequence of ingestion and digestion (Galef, Mason, Preti, \& Bean, 1988; Galef \& Stein, 1985).

The importance of social influence in the development of adaptive dietary repertoires by rats (and by other omnivorous rodents; Choleris et al., 1998; Galef et al., 1998; Post, McDonald, \& Reichman, 1998; Valsecchi, Choleris, Moles, Guo, \& Mainardi, 1996; Valsecchi \& Galef, 1989; Valsecchi, Mainardi, Sgolfo, \& Taticchi, 1989) can be inferred from the multiplicity of social learning processes that have been found to affect rats' diet selections (see Galef, 1996, for review). Previous discoveries of processes supporting social learning about foods by rats have resulted from experiments designed on the assumption that the tendency to use socially acquired information when foraging evolved in response to challenges experienced in natural circumstances (Galef, 1990). Experiments based on this adaptationist hypothesis can have either of two outcomes: (1) They can provide evidence that naive rats faced with a particular challenge use information extracted from conspecifics to direct their subsequent

This work was supported by a grant from the Natural Sciences and Engineering Research Council of Canada. Correspondence should be addressed to B. G. Galef, Jr., Department of Psychology, McMaster University, Hamilton, ON, Canada L8S 4K1 (e-mail: galef@mcmaster.ca). foraging (Galef \& Wigmore, 1983), or (2) they can suggest that naive rats do not use information acquired from conspecifics to respond to the demands of a particular foraging situation (Galef, McQuoid, \& Whiskin, 1990; Galef, Wigmore, \& Kennett, 1983). Either outcome is informative. Evidence of rats' use of socially acquired information leads to analyses of the processes supporting the observed social learning, and on occasion, to discovery of previously unsuspected social learning mechanisms (Galef, 1993). Failure of subjects to use social information to increase their foraging efficiency suggests either an absence of relevant information in the social environment or limits on subjects' ability to extract and use available information (see, e.g., Galef et al., 1983).

In Experiment 1, we explored the possibility that observer rats would respond differently to information extracted from demonstrator rats that (Experiment 1A) had either exhausted or not exhausted the available supply of a food, or (Experiment 1B) had eaten foods containing adequate or inadequate amounts of protein. The experiments were based on the hypotheses that, in the world outside the laboratory, naive rats would benefit if they could learn to seek foods eaten (Experiment 1A) by conspecifics exploiting an ample food source rather than a depleted one, or (Experiment 1B) by protein-replete rather than proteindeprived conspecifics.

In Experiment 2, we determined whether observer rats would respond differently to information provided by conspecific demonstrators that had previously provided either trustworthy or misleading information about the safety of potential ingesta. Again, it seemed reasonable to hypothesize that rats would benefit by treating information extracted from conspecifics known to ingest safe foods differently from information extracted from conspecifics with a history of ingesting toxic substances. 


\section{EXPERIMENT 1}

A honey bee returning to its hive after feeding in a nectar-rich patch of flowers recruits more foragers to that patch than does a hive mate that has been exploiting a relatively poor source of food. Bees feeding from concentrated sucrose solutions are more likely to dance, and to dance longer, and therefore to recruit more foragers than are bees feeding from relatively dilute sucrose solutions (Seeley, 1995). Perhaps Norway rats returning to their harborage sites after foraging can also provide conspecifics with information regarding the relative value of the food source they have been exploiting.

In the present experiment, we asked whether demonstrator rats that had fed from an excess of high-quality food were more likely to recruit observer rats to ingest that food than were demonstrator rats that had either (Experiment 1A) exhausted available supplies of a high-quality food or (Experiment 1B) had fed from an adequate supply of low-quality food. In the former case (Experiment 1A), demonstrators might evince either their hunger or their frustration at exhausting available supplies of food before eating their fill; in the latter case (Experiment 1B), demonstrators might emit either behavioral or olfactory cues indicating that they were ill (Lavin, Freise, \& Coombes, 1980).

\section{Method}

\section{Subjects}

Ninety-four experimentally naive, 42-day-old female LongEvans rats obtained from Charles River Canada (St. Constant, PQ) served as observers. A further 18850 - to 56-day-old female rats that had served as observers in other experiments on diet choice served here as demonstrators. We randomly assigned 54 observers and 108 demonstrators to Experiment $1 \mathrm{~A}$ and a further 40 observers and 80 demonstrators to Experiment $1 \mathrm{~B}$.

All subjects were maintained throughout both experiments in a temperature- and humidity-controlled colony room illuminated for $12 \mathrm{~h} /$ day. All subjects had ad-lib access to water throughout the experiments, but were fed on schedule, as indicated in the the Procedure section.

\section{Diets}

Experiment 1A. We fed two diets (Diet Cin and Diet Coc) to subjects in Experiment 1A. We prepared Diet Cin by mixing $10 \mathrm{~g}$ of bulk, ground cinnamon (Horn of Plenty, Dundas, $\mathrm{ON}$ ) with $1,000 \mathrm{~g}$ of powdered Purina Rodent Laboratory Chow 5001 (RalstonPurina Canada, Woodstock, ON). Diet Coc was prepared by mixing $20 \mathrm{~g}$ of Hershey's Pure Cocoa (Hershey Canada Inc., Mississauga, ON) with 1,000 $\mathrm{g}$ of chow.

Experiment 1B. We used a protein-free, basal mix (Diet NoP; catalog no. TD 86146; Teklad Diets, Madison, WI) as the main ingredient of six diets of varying protein content and flavor that we fed to subjects in Experiment 1B. We prepared high-protein diet (Diet HiP) by mixing $200 \mathrm{~g}$ high-protein casein (catalog no. 160030; Teklad Diets, Madison, WI) with $800 \mathrm{~g}$ of Diet NoP to make a diet with a $17.5 \%$ protein content. (A diet containing $12 \%$ protein by weight is considered adequate for young rats; Guide to the Care and Use of Experimental Animals, 1980.)

We then made diets NoP-Cin and NoP-Coc by mixing, respectively, $10 \mathrm{~g}$ of cinnamon or $20 \mathrm{~g}$ of cocoa with $1,000 \mathrm{~g}$ of Diet NoP, and we prepared diets HiP-Cin and HiP-Coc by mixing either $10 \mathrm{~g}$ of cinnamon or $20 \mathrm{~g}$ of cocoa with $1,000 \mathrm{~g}$ of Diet HiP.

\section{Apparatus}

Throughout Experiments $1 \mathrm{~A}$ and $1 \mathrm{~B}$, we housed demonstrators and observers individually in stainless steel hanging cages measuring $34.3 \times 20.3 \times 20.3 \mathrm{~cm}$. All subjects ate from semicircular stainless steel cups ( $10 \mathrm{~cm}$ in diameter $\times 5 \mathrm{~cm}$ deep) filled less than half full to eliminate spillage.

\section{Procedure}

Experiment 1A. To begin Experiment 1A, we weighed all 108 demonstrator rats and, to ensure that they would eat when given the opportunity to do so, placed the demonstrators on a 23 -h schedule of food deprivation. While on this initial feeding schedule, demonstrators ate unadulterated powdered Purina chow for $1 \mathrm{~h} /$ day for 2 consecutive days.

Following a third, 23-h period of food deprivation, we gave equal numbers of demonstrators assigned to the experimental condition access for $1 \mathrm{~h}$ to (1) a surplus ( $30 \mathrm{~g}$ ) of Diet Cin, (2) a surplus ( $30 \mathrm{~g})$ of Diet Coc, (3) a limited amount ( $3 \mathrm{~g}$ ) of Diet Cin, or (4) a limited amount $(3 \mathrm{~g})$ of Diet Coc.

We gave 30 demonstrators assigned to the control condition access to a surplus of unadulterated, powdered Purina chow (the base diet from which we made both Diets $\mathrm{Cin}$ and $\mathrm{Coc}$ ) and gave the 30 remaining demonstrators assigned to the control condition access to either $3 \mathrm{~g}$ of Diet Cin or $3 \mathrm{~g}$ of Diet Coc.

Immediately following the third 1-h period of demonstrator feeding, we placed 2 demonstrators in the cage of each observer and then left demonstrators and observers free to interact for $30 \mathrm{~min}$. Each observer assigned to the experimental condition interacted with I demonstrator fed Diet Cin and 1 demonstrator fed Diet Coc. For 12 of these observers, the demonstrator fed Diet Cin had eaten from a surplus of Diet Cin while the demonstrator fed Diet Coc had been given access to only $3 \mathrm{~g}$ of that diet. Each of the remaining 12 observers assigned to the experimental condition interacted with 1 demonstrator that had eaten from a surplus of Diet $\mathrm{Coc}$ and 1 demonstrator that had been given access to only $3 \mathrm{~g}$ of Diet Cin.

Fifteen of the observers assigned to the control condition interacted with a demonstrator that had eaten $3 \mathrm{~g}$ of Diet $\mathrm{Cin}$ and 1 demonstrator that had eaten from a surplus of unadulterated, powdered chow during the hour immediately preceding interaction of demonstrators and observers. The remaining 15 observers assigned to the control condition interacted with 1 demonstrator fed $3 \mathrm{~g}$ of Diet $\mathrm{Coc}$ and 1 demonstrator that had fed from a surplus of unadulterated, powdered chow.

At the end of the 30-min period of interaction between demonstrators and observers, we removed demonstrators from the experiment. We then offered each of the 54 observers a choice between weighed samples of Diets Cin and Coc.

Twenty-four hours later, we removed the two food cups from each observer's cage and weighed them. Finally, we calculated, for each observer, the percentage of its total food intake that was Diet Cin.

Experiment 1B. The design of Experiment IB was similar to that of Experiment $1 \mathrm{~A}$ except that instead of giving demonstrators access to either a surplus or limited amount of distinctively flavored foods, we instead gave them access to a surplus of either a distinctively flavored protein-free or protein-rich diet.

To allow demonstrators to experience the consequences of ingesting their respective diets, we first gave equal numbers of demonstrators ad-lib access to Diet NoP-Cin, Diet NoP-Coc, Diet HiP-Cin, or Diet HiP-Coc for 2 days. We then placed each demonstrator on a 23-h schedule of food deprivation and fed it the same diet that it had eaten for the preceding 2 days for $1 \mathrm{~h} /$ day for each of 3 additional days.

Immediately after the 80 demonstrators had finished eating on the 3 rd day of scheduled feeding, we placed 2 of them in the home cage of each observer. Twelve observers assigned to the experimental condition interacted, for $30 \mathrm{~min}$, with 1 demonstrator that had just eaten Diet HiP-Cin and 1 that had just eaten Diet NoP-Coc. 


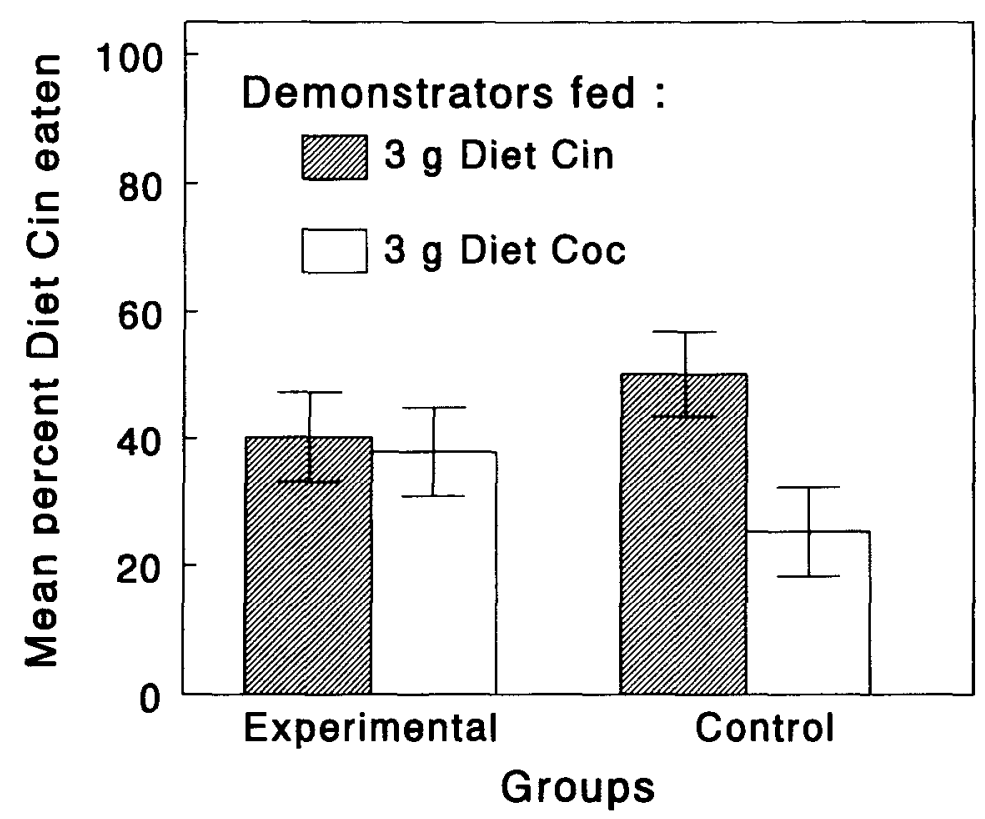

Figure 1. Mean percentage of Diet Cin eaten by observer rats in Experiment $1 \mathrm{a}$ that interacted with pairs of demonstrator rats fed either (experimental conditions) $30 \mathrm{~g}$ of Diet Cin and $3 \mathrm{~g}$ of Diet Coc or $30 \mathrm{~g}$ of Diet Coc and $3 \mathrm{~g}$ of Diet Cin, or (control conditions) $3 \mathrm{~g}$ of either Diet Cin or Diet Coc and a surplus of unadulterated Purina chow. Error bars, \pm 1 SEM.

The remaining 12 observers assigned to the experimental condition each interacted with 1 demonstrator that had just eaten Diet NoPCin and $I$ that had just eaten Diet HiP-Coc.

The 16 observers assigned to the control condition and their demonstrators were treated exactly as were the 24 observers assigned to the experimental condition, except that each observer in the control condition interacted with 1 demonstrator fed Diet NoP and 1 fed either Diet NoP-Cin or Diet NoP-Coc.

At the end of the 30-min period of interaction between observers and their demonstrators, we removed demonstrators from the experiment and gave each observer in both experimental and control conditions a choice, for $23 \mathrm{~h}$, between weighed samples of Diet HiP-Cin and Diet HiP-Coc. At the end of this 24-h test period, we weighed the two food bowls in each observer's cage and calculated the percentage of each observer's total food intake that was Diet HiP-Cin.

\section{Results and Discussion}

\section{Experiment 1A}

The 54 demonstrators given access to $3 \mathrm{~g}$ of food ate all of the food available to them $( \pm .1 \mathrm{~g})$, while the 54 demonstrators given access to $30 \mathrm{~g}$ of food ate an average $( \pm 1 S E M)$ of $5.6 \pm .2 \mathrm{~g}$.

Data were lost from 1 observer assigned to the experimental condition when, as a result of a blockage in the spout of its water bottle, it failed to eat after interacting with its demonstrators.

The main results of Experiment $1 \mathrm{~A}$ are presented in Figure 1, which shows the mean amount of Diet Cin eaten by observers assigned to experimental and control conditions. As can be seen in Figure 1, observers assigned to the experimental condition ate roughly equal amounts of the diet eaten by the demonstrator offered an excess of food and the demonstrator that had exhausted available food during its l-h feeding period [Mann-Whitney $U$ test, $U(12,11)=63$, n.s.].

As is also evident from inspection of Figure 1, those observers assigned to the control condition (i.e., those observers that had interacted simultaneously with 2 demonstrators, 1 fed a limited amount of flavored diet and 1 fed a surplus of unadulterated diet) exhibited an enhanced preference for the flavored diet that 1 of their demonstrators had eaten [Mann-Whitney $U$ test, $U(15,15)=55$, $p<.02]$.

The finding that subjects in the control condition showed a preference during testing for the flavored diet eaten by 1 of their demonstrators indicates that presence of 2 demonstrators when demonstrators and observers interacted was not the cause of observers in the experimental condition failing to prefer the diet eaten by whichever of their demonstrators had eaten a surplus of diet. Observers in the experimental condition simply failed to respond differently to demonstrators that had either exhausted their supply of food or fed from a surplus of food.

\section{Experiment 1B}

Between the start of the experiment and the 30-min period of interaction between demonstrator rats and their respective observers, demonstrators that we had fed protein-rich diets lost an average of $3.1 \pm .8 \%$ of their 


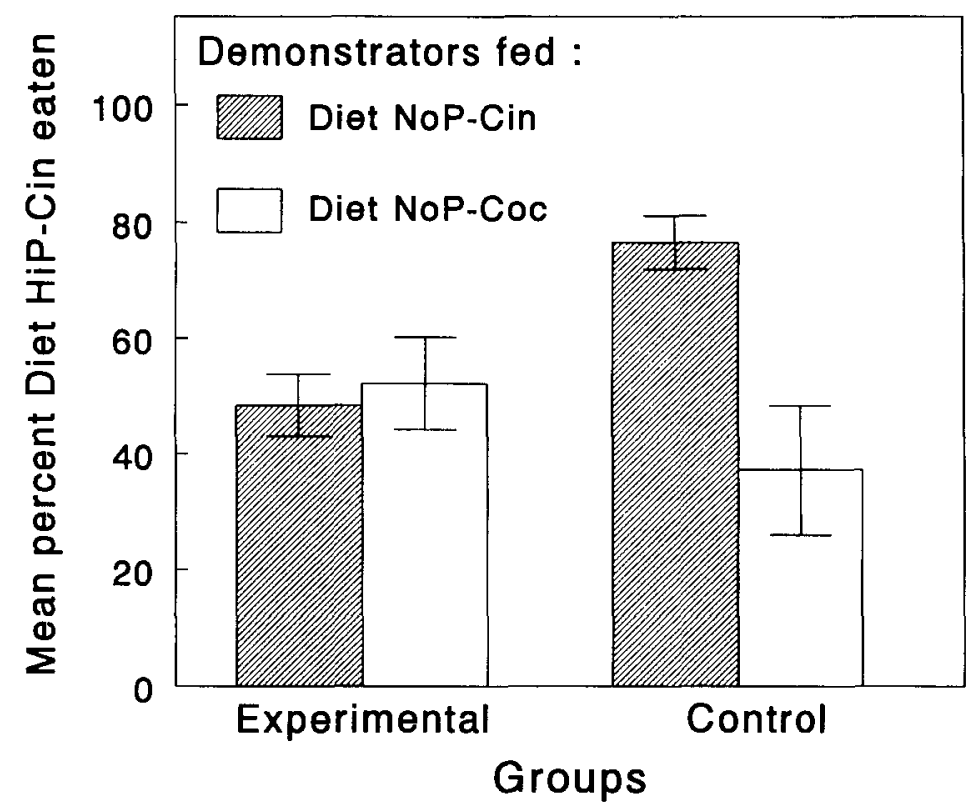

Figure 2. Mean percentage of Diet HiP-Cin eaten by observer rats in Experiment 1 a that interacted with (experimental conditions) 1 demonstrator fed Diet NoP-Cin and a 2nd demonstrator fed Diet HiP-Coc or 1 demonstrator fed Diet NoP-Coc and a 2nd demonstrator fed Diet HiP-Cin or (control conditions) either a demonstrator fed diet NoP-Cin and a 2nd demonstrator fed Diet NoP or a demonstrator fed Diet NoP-Coc and a 2 nd demonstrator fed Diet NoP. Error bars, \pm 1 SEM.

body weight, presumably as a result of scheduled feeding. Demonstrators treated identically, but fed protein-free diet rather than protein-rich diet, lost an average of $14.7 \pm .7 \%$ of their body weight [Mann-Whitney $U$ test, $U(24,24)=$ $0, p<.0001]$. We conclude that, as intended, demonstrators fed protein-deficient diet were experiencing from deficiency when they interacted with their observers.

The main results of Experiment IB are presented in Figure 2, which shows the mean amount of Diet HiP-Cin eaten by observers assigned to experimental and control conditions. As can be seen in Figure 2, observer rats assigned to the experimental condition ate as much Diet HiP-Cin after interacting with a protein-deficient demonstrator that had eaten cinnamon-flavored diet as after interacting with a protein-replete demonstrator that had eaten cinnamon-flavored diet [Mann-Whitney $U$ test, $U(12,11)=36$, n.s.]. Observers assigned to the control condition, on the other hand, were influenced in their food choices by the flavored diet fed to one of their 2 demonstrators $[U(8,8)=9, p<.01]$.

As was the case in Experiment $1 \mathrm{~A}$, the results of the control condition indicate that social learning about foods can take place in the conditions of the experiment. This finding is also consistent with the results of several experiments (Chou \& Richerson, 1992; Kuan \& Colwill, 1997) showing that observer rats presented simultaneously with 2 or more demonstrators, some fed a cinnamonflavored and others a cocoa-flavored diet, can respond differently to the foods eaten by each demonstrator. Kuan and Colwill, for example, showed that observer rats that had interacted simultaneously with 2 demonstrator rats, 1 fed cinnamon-flavored and the other cocoa-flavored diet, subsequently avoided whichever diet had been eaten by the demonstrator that was ill while interacting with its observer.

In Experiment 1A, either protein-deprived demonstrator rats did not provide evidence of their illness in a way that was utilizable by their observers or observer rats failed to associate the scent of cinnamon or cocoa with their ill demonstrator. Whatever the reason, observers did not respond differently to demonstrators eating protein-rich food and demonstrators eating protein-poor food.

Taken together, the results of Experiments $1 \mathrm{~A}$ and $1 \mathrm{~B}$ fail to provide evidence that observer rats can use information extracted from conspecific demonstrators as to either the nutritional value of foods those demonstrators ate or the amount of food that was available to them.

\section{EXPERIMENT 2}

Within an established colony of Norway rats, one would expect to find not only long-time residents that have learned to select nutritious, safe foods from among the plethora of available, ingestible substances, but also juveniles or recent immigrants ingesting useless or toxic substances as they sample unfamiliar, potential foods and learn about the nutritive value of each. It seems reasonable to hypothesize that, in natural environments, the for- 
aging efficiency of members of rat colonies would be increased if they could discriminate those conspecifics that were reliably selecting safe, nutritious foods to eat from those that had a history of ingesting unsuitable substances.

In the present experiment, we first provided each observer rat with opportunities to learn that the information provided by 1 demonstrator was "untrustworthy" (i.e., that demonstrator ingested noxious substances), and that information provided by a 2 nd demonstrator was "trustworthy" (i.e., that demonstrator ate only safe, nutritious foods). To teach an observer that 1 of its demonstrators ate noxious substances, we gave the observer foods to eat that its untrustworthy demonstrator had eaten, and then made the observer ill. We knew from numerous pilot studies that a single pairing of ingestion of any of the flavored diets used in Experiment 2 with illness produces a profound aversion to that flavored diet (authors' unpublished observation). To teach an observer that a 2 nd demonstrator was trustworthy, we gave the observer access to diets that its trustworthy demonstrator had eaten so that the observer could experience the positive postingestional consequences of eating those diets.

After each observer had learned about its trustworthy and untrustworthy demonstrators, we allowed it to interact simultaneously with both demonstrators after each had eaten a distinctively flavored food unfamiliar to the observer. Last, we determined whether trustworthy and untrustworthy demonstrators differed in their influence on the food choices of their observers.

\section{Method}

\section{Subjects}

Fifty-six experimentally naive, 42-day-old female Long-Evans rats purchased from Charles River Canada served as observers. An additional 112, 50- to 60-day-old rats that had participated in other experiments on social induction of food preference served as demonstrators. We randomly assigned observers and demonstrators to experimental (16 observers and 32 demonstrators) and control ( 40 observers and 80 demonstrators) conditions.

\section{Diets}

We prepared six distinctively flavored diets by mixing $1,000 \mathrm{~g}$ of powdered Purina Rodent Laboratory Chow 5001 with $10 \mathrm{~g}$ of McCormick's Fancy Ground Cinnamon (Diet Cin), $20 \mathrm{~g}$ of Hershey's Pure Cocoa (Diet Coc), $10 \mathrm{~g}$ of bulk ground anise (Diet Ani), $20 \mathrm{~g}$ of bulk ground marjoram (Diet Mar), $7 \mathrm{~g}$ of bulk ground thyme (Diet Thy), or $7 \mathrm{~g}$ of bulk ground rosemary (Diet Ros). All bulk ground herbs and spices were obtained from Horn of Plenty (Dundas, ON).

In previous experiments, we have found robust social transmission of flavor preference for each of the six flavors used in the present experiment (Galef \& Whiskin, 1992).

\section{Apparatus}

We housed demonstrators and observers individually in stainless steel wire-mesh hanging cages measuring $34.3 \times 20.3 \times 20.3 \mathrm{~cm}$ and presented food to subjects in semicircular, stainless steel cups $(10 \mathrm{~cm}$ in diameter $\times 5 \mathrm{~cm}$ deep) that we half filled with food.

\section{Procedure: Experimental Condition}

Days 1 to 3: Scheduled feeding. For the first 3 days of the experiment, we maintained both demonstrators and observers on a 23-h schedule of food deprivation and, for $1 \mathrm{~h}$ each day, fed all 96 subjects unadulterated powdered Purina chow.

Day 4: Creating an untrustworthy demonstrator. On the 4th day of the experiment, we first weighed each observer so that we could calculate an appropriate dose of toxin with which to inject it. Then, for $30 \mathrm{~min}$, we fed 16 demonstrators Diet Ros and the 16 remaining demonstrators Diet Thy.

Next, we placed 1 demonstrator fed Diet Thy and 1 demonstrator fed Diet Ros into the home cage of each of the 16 observers and left observer and demonstrator to interact for $30 \mathrm{~min}$. At the end of this 30-min period of interaction between demonstrators and observers, we returned each demonstrator to its home cage, and for $1 \mathrm{~h}$, offered each observer a food cup containing Diet Thy.

At the end of this 1-h observer-feeding period, we removed the food cup from each observer's cage and injected it intraperitoneally with $1.0 \%$ of its body weight, .13 molar lithium-chloride solution. Thus, each observer interacted with 2 demonstrators, 1 of which had eaten a diet that its observer subsequently learned was toxic.

Day 5: Creating a trustworthy demonstrator. On Day 5, each observer had an opportunity to learn that 1 of its demonstrators had eaten a safe food. The procedure was identical to that we had used on Day 4 except that on Day 5, after each observer interacted with the same 2 demonstrators with which it had interacted on Day 4, each fed the same diet that it had eaten on Day 4, the observer was offered, for $1 \mathrm{~h}$, Diet Ros the diet that the demonstrator that was to be that observer's trustworthy demonstrator had eaten.

Day 6: A second demonstration by the untrustworthy demonstrator. The procedure on Day 6 was identical to that on Day 4 except that on Day 6 (1) each observer's trustworthy demonstrator ate Diet Ani and each observer's untrustworthy demonstrator ate Diet Mar, and (2) we offered each observer Diet Mar to eat for $1 \mathrm{~h}$ before we injected it with lithium-chloride solution. Thus, by the end of Day 6, each observer had interacted with an untrustworthy demonstrator that had twice eaten foods that its observer later learned were toxic.

Day 7: A second demonstration by the trustworthy demonstrator. The procedure on Day 7 was identical to that on Day 5 except that on Day 7, after each observer interacted with its trustworthy demonstrator fed Diet Ani and its untrustworthy demonstrator fed Diet Mar, we offered observers diet Ani for $1 \mathrm{~h}$. Thus by the end of Day 7 , each observer had interacted with a trustworthy demonstrator that had twice eaten foods its observer later learned were safe.

Day 8: Testing. Each observer again interacted for $30 \mathrm{~min}$ with both its trustworthy and untrustworthy demonstrators. However, on Day 8, we fed either the trustworthy or untrustworthy demonstrator with which each observer interacted Diet Cin and its other demonstrator Diet Coc. The diets fed to trustworthy and untrustworthy demonstrators were counterbalanced across observers.

After each observer had interacted with its demonstrators, we offered it a choice, for $24 \mathrm{~h}$, between weighed samples of Diet Cin and Diet Coc.

Day 9: The dependent variable. The experimenter weighed the two food cups in each observer's cage $24 \mathrm{~h}$ after the start of testing and calculated the percentage of its intake that was Diet Cin.

\section{Procedure: Control Condition}

Subjects assigned to the control condition were treated identically to those assigned to the experimental condition except that on Day 8 , the day of testing, 40 observers interacted simultaneously with both their trustworthy and untrustworthy demonstrators after 1 demonstrator had been fed either Diet Cin or Diet Coc and the other had been fed unadulterated, powdered Purina chow. The diet fed to the trustworthy and untrustworthy demonstrators with which each observer interacted was counterbalanced across observers, dividing observers into four groups ( $n=10$ /group) whose trustworthy or untrustworthy demonstrators were fed either Diet Cin or Diet Coc. 


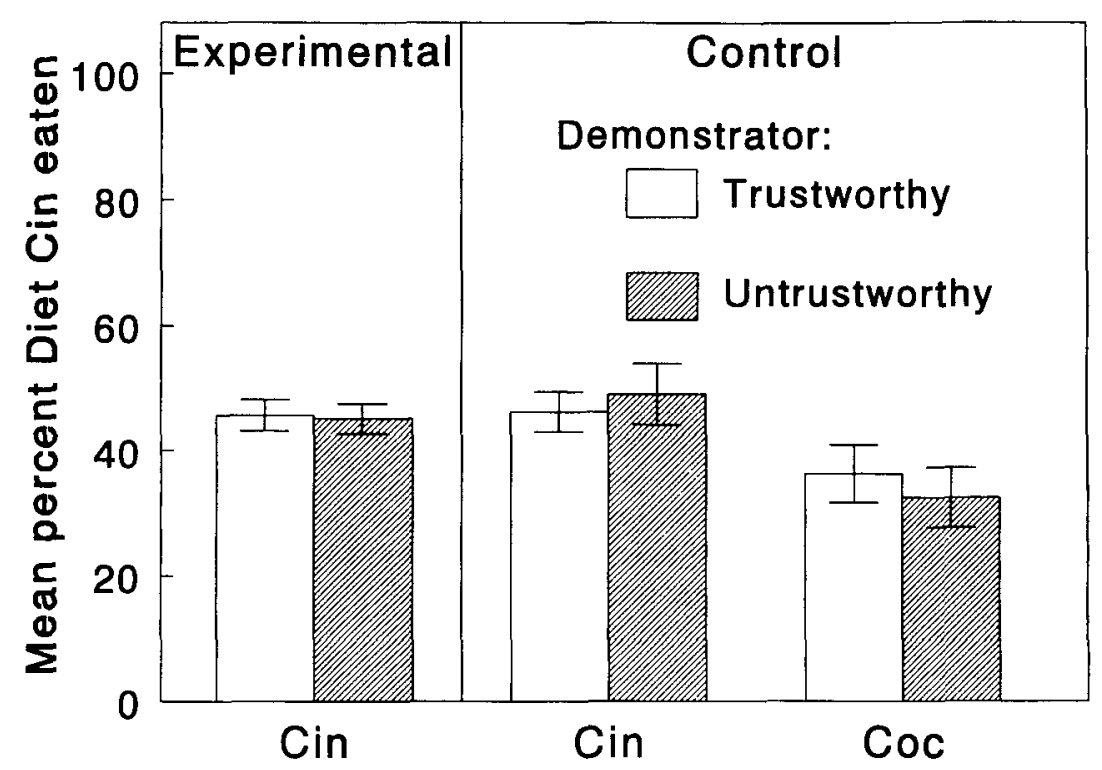

Flavored Diet fed to Demonstrators

Figure 3. Mean percentage of Diet Cin eaten by observer rats in Experiment 2 that interacted with trustworthy and untrustworthy demonstrator rats either 1 (control condition) or both (experimental condition) of which had eaten a flavored diet. Error bars, \pm 1 SEM.

\section{Results and Discussion}

We found no statistically significant difference between the amount of diet eaten by trustworthy and by untrustworthy demonstrators on any of the days when demonstrators interacted with observers (Mann-Whitney $U$ tests, n.s.).

The main results of Experiment 2 are presented in Figure 3 , which shows the amount of Diet Cin eaten by observers whose trustworthy or untrustworthy demonstrators ate Diet Cin before interacting with observers. As is evident from inspection of Figure 3, trustworthy demonstrators had no more influence on the food choices of observers assigned to the experimental condition than did untrustworthy demonstrators [Mann-Whitney $U$ test, $U(8,8)=42$, n.s.].

As can also be seen in Figure 3, the procedure of repeatedly exposing observers to demonstrators and twice subjecting them to toxicosis did not interfere with social induction of food choice in observers assigned to the control condition. In the control condition, although as expected, observers whose demonstrators had eaten Diet Cin ate more Diet $\mathrm{Cin}$ than did observers whose demonstrators had eaten Diet Coc [Mann-Whitney $U$ test, $U(10,10)=$ $107, p<.01]$, there was no effect of reliability of demonstrators fed Diet Cin or Diet Coc on the amount of Diet Cin eaten by respective observers (Mann-Whitney $U$ tests, both $U_{\mathrm{s}}(10,10)>44$, n.s.].

\section{GENERAL DISCUSSION}

Observer rats reliably extract diet-identifying information from conspecific demonstrators and use that in- formation when subsequently selecting foods to eat (Galef \& Wigmore, 1983). However, in most circumstances, observer rats respond in the same way to diet-identifying information acquired from healthy, active demonstrators and from either poisoned (Galef et al., 1990; Galef et al., 1983; Grover et al., 1988; Kuan \& Colwill, 1997) or unconscious demonstrators (Galef \& Wigmore, 1983; Galef \& Stein, 1985). The results of Experiment 1 in the present series suggest that nutrient-deprived demonstrators (Experiment 1B) and demonstrators exploiting limited supplies of food (Experiment IA), like poisoned or unconscious demonstrators, are as effective as are well-fed, healthy demonstrators in influencing their respective observers' food choices.

The results of Experiment 2 suggest that observer rats are also unable to discriminate between information acquired from demonstrators that, in the past, have provided either useful information or misleading information concerning the safety of potential ingesta.

Of course, such negative findings must be accepted with caution. Further investigations might reveal circumstances under which observer rats do discriminate among demonstrators based on their previous reliability as informants or their relative success in finding adequate supplies of nutritive foods to ingest. It should, however, be kept in mind that evidence of social enhancement of food intake in Norway rats has proven easy to find in a wide variety of circumstances (see, e.g., Galef et al., 1983: Grover et al., 1988; Heyes \& Durlach, 1990; Posadas-Andrews \& Roper, 1983), while despite considerable effort (only a part of which is reported here), we have had no success 
in finding circumstances where observers respond differently to information acquired from trustworthy or untrustworthy demonstrators, demonstrators exploiting rich or poor feeding sites, or demonstrators that have eaten protein-deficient or protein-sufficient diets.

Taken together, (1) the ease of demonstrating social induction of food preference in both rats and other species of laboratory rodent and (2) the difficulty of finding evidence that observers discriminate among demonstrators with different ingestive histories suggest that rats learn socially about foods that their fellows are eating, but often do not treat information extracted from informants with varying histories differently, even when such discrimination might prove useful. Thus, as we continue to explore the nature of social influences on Norway rats' feeding behavior, we are repeatedly led to the conclusion that information extracted from demonstrators by observers is used to identify and increase observers' intake of foods their demonstrators have eaten, but not for much else.

\section{REFERENCES}

Choleris, E., Valsecchi, P., Wang, Y., Ferrari, P., Kavaliers, M., \& MAINARD, M. (1998). Social learning of food preferences in male and female Mongolian gerbils (Meriones unguiculatus) is facilitated by the benzodiazepine anxiolytic, chlodiazepoxide. Pharmacology, Biochemistry \& Behavior, 60, 575-584.

Chou, L.-S., \& Richerson, P. J. (1992). Multiple models in transmission of food selection by Norway rats, Rattus norvegicus. Animal Behaviour, 44, 337-343.

GALEF, B. G., JR. (1990). An adaptationist perspective on social learning, social feeding, and social foraging in Norway rats. In D. A. Dewsbury (Ed.), Contemporary issues in comparative psychology (pp. 55-79). Sunderland, MA: Sinauer.

GALEF, B. G., JR. (1993). Functions of social learning about foods by Norway rats: A causal analysis of effects of diet novelty on preference transmission. Animal Behaviour, 46, 257-265.

GALEF, B. G., JR. (1996). Social influences on food preferences and feeding behavior of vertebrates. In E. D. Capaldi (Ed.), Why we eat what we eat: The psychology of eating (pp. 233-266). Washington, DC: American Psychological Association.

Galef, B. G., Jr., Mason, J. R., Preti, G., \& Bean, N. J. (1988). Carbon disulfide: a semiochemical mediating socially induced diet choice in rats. Physiology \& Behavior, 42, 119-124.

GALEF, B. G., JR., McQuoid, L. M., \& Whiskin, E. E. (1990). Further evidence that Norway rats do not socially transmit learned aversions to toxic baits. Animal Learning \& Behavior, 18, 199-205.
Galef, B. G., JR., Rudolf, B., Whiskin, E. E., Choleris, E., MainARDi, M., \& VAlSECCHI, P. (1998). Familiarity and relatedness: Effects on social learning about foods by Norway rats and Mongolian gerbils. Animal Learning \& Behavior, 26, 448-454.

GALEF, B. G., JR., \& STEIN, M. (1985). Demonstrator influence on observer diet preference: Analysis of critical social interactions and olfactory signals. Animal Learning \& Behavior, 13, 31-38.

GALEF, B. G., JR., \& Whiskin, E. E. (1992). Social transmission of information about multiflavored foods. Animal Learning \& Behavior, 20, 56-62.

Galef, B. G., JR., \& WiGMORE, S. W. (1983). Transfer of information concerning distant foods: A laboratory investigation of the "informationcentre" hypothesis. Animal Behaviour, 31, 748-758.

Galef, B. G., JR., Wigmore, S. W., \& KenNett, D. J. (1983). A failure to find socially mediated taste-aversion learning in Norway rats $(R$. norvegicus). Journal of Comparative Psychology, 97, 358-363.

Grover, C. A., Kixmiller, J. S., Erickson, C. A., Becker, A. H., Davis, S. F., \& NALLAN, G. B. (1988). The social transmission of information concerning aversively conditioned liquids. Psychological Record, 38, 557-566.

Guide to the care and use of experimental animals. (1980). Ottawa: Canadian Council on Animal Care.

HEYES, C. M., \& DURLACH, P. J. (1990). Social blockade of taste-aversion learning in Norway rats (Rattus norvegicus): Is it a social phenomenon? Journal of Comparative Psychology, 104, 82-87.

KuAN, L.-A., \& ColwILL, R. M. (1997). Demonstration of a socially transmitted taste aversion in the rat. Psychonomic Bulletin \& Review, 4, 374-377.

Lavin, M. J., Freise, B., \& Coombes, S. (1980). Transferred flavor aversions in adult rats. Behavioral \& Neural Biology, 28, 15-33.

Posadas-Andrews, A., \& Roper, T. J. (1983). Social transmission of food preferences in adult rats. Animal Behaviour, 31, 265-271.

Post, D. M., McDonald, M. W., \& Reichman, O. J. (1998). Influence of maternal diet and perishability on caching and consumption behavior of juvenile eastern woodrats. Journal of Mammalogy, 79, 156162.

SEELEY, T. D. (1995). The wisdom of the hive: The social physiology of honey bee colonies. Cambridge, MA: Harvard University Press.

Valsecchi, P., Choleris, E., Moles, A., Guo, C., \& Mainard, M. (1996). Kinship and familiarity as factors affecting social transfer of food preferences in adult Mongolian gerbils (Meriones unguiculatus). Journal of Comparative Psychology, 110, 243-251.

VALSECCHI, P., \& GALEF, B. G., JR. (1989). Social influences on the food preferences of house mice. International Journal of Comparative Psychology, 2, 245-256.

ValsecChi, P., Mainardi, M., Sgolfo, A., \& Taticchi, A. (1989). Maternal influences on food preferences in weanling mice (Mus domesticus). Behavioural Processes, 19, 155-166.

(Manuscript received October 1, 1998; revision accepted for publication January 19, 1999.) 